\title{
SURGICAL PATHOLOGY AND THERAPEUTICS, AND OPERATIVE SURGERY.
}

23. Use of Chloride of Zinc in Surgical Operations for Removal of Cancerous Tumours.-C. De MoraAn, Esq., Surgeon to the Middlesex Hospital, has published (British and For. Med.-Chirurg. Rev., Jan. 1866) an extremely interesting paper on this subject. "The use of the chloride of zinc," he states, "was adopted in the first instance after removal of malignant tumours by the knife, for reasons which apply exclusively to operations on such growths. The results which were obtained led me to resort to its application in all wounds, whether made in operations or accidentally. Whether the special object for which it was at first used is attained even partially can only be proved by very long experience, but the general effects have been so immediately and uniformly beneficial in a large number of cases in which it has been applied, as to satisfy me that in the treatment of wounds the chloride of zinc is an agent of great value, well "worthy of careful trial by surgeons."

Mr. De Morgan expresses his conviction "that in most cases of recurrence [of cancer], where the tumour has even been to all appearance entirely removed, the recurrence has been due to the presence of minute cancer elements which have escaped the knife, or, as is perhaps as frequently the case, to germs being set free by section of the tumour or of diseased tissne around it during the operation, and their implantation into the newly-cut structures. That this is the case is, I think, shown by the fact that where a voluminous breast with only a small tumour imbedded in it is removed, and the incision is consequently very long in proportion to the size of the tumour, the recurrence frequently very long in proportion takes place along the whole of cicatrix, not especially in that part which corresponds to the site of the tuniour. If, then, the view which has been so ably advocated by Mr. Moore be correct, that cancer is a loeal disease which becomes disseminated from the point of its first invasion, the praetice of early extirpation cannot be too much insisted on. A tumour, as soon as it is recognized as cancerous, should be removed, if practicable, at once. A few days, even, may make a difference; not, perhaps, to any extent in the size of the days, even, may make a difierence; not, perhas, its apparent limits. It would be better even to extirpate doubtful tumours, some of which might turn out on after examination not to be cancerous, than to leave them to develop thenselves, and then to find, too late, perhaps, for help, the charaeters of malignaniy becoming marked. These views, which lad often been diseussed amongst the members of the surgical staff at the Middlesex, encouraged Mr. Moore, in a severe case of breast caucer, to apply the solid chloride of zinc to a large portion of the surface of the wound made in its extirpation, as he had effectually done in a case of extensive epithelioma of the face, which he showed at one of the meetings of the British Medical Association in London. This was done in April, 1864."

It occurred to Mr. De Morgan that "one might obtain the benefits which were sought by using the caustic in a less active form, and that a strong lotion of the chloride of zinc applied freely over the whole exposed surface, after an operation for the removal of cancer, would penetrate to some little extent beyond the limits of the section, and would at least destroy any floating particles of the disease which might adhere to it without endangering the vitality of the whole thickness of the flap.

"The first case in which I tried this plan was that of a lady, forty-one years of age, who had a cancerous tumour in the right breast. She was well nourished and healthy, and had noticed the tumour about a twclvemonth. In the axilla was a gland slightly enlarged, but not hard, and in all respects the case was a favourable one for operation. The operation was performed in March, 1865. The strength of the solution employed was twenty grains of the chloride of zine to the ounce of water; the whole surface of the wound was well sponged with it. The blood which still oozed was, as nsual. rendered of a bright pink colour, and the contact of the solution at once caused a more free oozing from the 
exposed surfaces; otherwise no effect was perceptible. The lotion was thoroughly pressed in with the sponge. and in a little time the surface became soft and creamy in feel, and this softness extended to a little depth-a line, perhaps. Here I stopped. not knowing how far I might venture witlout causing sloughing of the flaps of skin. My impression was that a superficial slough would form, and would be thrown off by degrees during the suppurating stage, which, I assumed, must of necessity ensue, and which. in fact. I rather desired. The edges of the wound were, nevertheless, put together with sutures, save at the outer part, which was left quite open, to allow of the free passage of the supposed inevitable pus. A compress was put over tlie wound to check the tendency to any further bleeding into the cavity. After recovering from the effects of the chloroform, she complained for two or three hours of smarting paiu; not more, I think, than is usually felt, and from that time she was entirely free from any pain at all. I thouglit it probable that on removing the compress. about eighteen hours after. the parts would be found swollen and angry, although the pain had been so slight; but instead of that, the circumstance most noticeable was the absence of even the usual amount of fulness. It wis evident that action, instead of being increased, had been dimiuished, one might almost say arrested, by the applicition. The skin, even up to the clit edge, looked and felt exactly like the slin of the other breast. Blood, in much about the sume quantity as is usually found after such an operation, had oozed from the wound; but it was pink and creamy in cliaracter, and what was especially remarkable was the entire abseuce of the peculiar odour which is generally found in blood which has been pent up beneath a compress for some hours. There was, in fact, no animal smell at all. Bnt what most struck me in the progress of the case was the absence of suppuration. The whole line of incision united in the course of forty-eight hours, except just at the outer angle, which discharged a very small quantity of the same pink, creamy-looking finid for a day or two more, and then liealed. The same absence of animal odour was noticed to the end. I certainly never saw a wonnd which did not heal absolutely by the first intention go through its process of cure so speedily or so quietly. The patient remains perfectly well to the present time.

"In cases of cancer on which I have subsequently operated I have used stronger lotions. In this first case the strength was 20 grains to the ounce. I next tried 30 grains, and then 40 to the ounce. With the stronger lotion a more rapid effect is produced, and the blood exudes more abuidantly, but this is only for a few seconds, otherwise much the same course of events has been seen as in the first case during the early period. Some have healed in the same rapid manner, in some there lias occurred an after suppuration, but in nono have any bad effects been seen.

"What the effect of this treatment may be in limiting the tendency to return after extirpation of cancer, can only be determined by time and numbers. If the views of the diffusion and transplantation of cancer germs before expressed have any truth, it cannot but be beneficial; for to some extent it certainly must alter the character of the exuded matters and of the remaining tissues. My own impression is, that in cancer it would be well to go beyond the point hitherto reached, and that this may be safely done, for the effect of the chloride of zine seems to be limited to the point with which it is brought into contact. It appears to produce very little irritation beyond that point, so that it may be worked into the inner surface of the flap till the tissue is softened to within a few lines of the surface withont risk to the vitality of the remainder."

The favourable way in which the wound healed in the case just related satisfied Mr. De M. that the application might be employed in other than cancerous cases. "There was one point," he remarks, "which especially struck me, as giving it great value in hospital practice; the perfect purity of the discharges from the wound during the first few days after an operation. It is well known that the presence of decomposing animal matter tends to bring any dead animal matter with which it may be in contact in to a rapid state of decomposition; and if this take place in a wound, it will certainly interfere for a time with the natural and healthy processes of cure, and may induce erysipelas or pyamia.

"That this decomposition does nsually occur is evinced by the peculiar sickly 
animal smell which is perceived wheucver a wouud which has been covered for a few hours is opened. When, on the contrary, a wound bas been fairly impregnated with the chloride lotiou, there is invariably an absence of any animal smell whatever for two or three days; and, unless some diseased tissue remain in the wound, there mas bc none throughout the healing. Were this the only advantage, it would be a great one; I believe that in onr hospital it has saved many a patient from erysipelas ; certainly we have been for the last eight months very free from it after operations, while just before it was very prevalent. But this may be an accidental coincideuce merely, and time and experience can alone determine how much is due to the treatment. It is not, however, the only advantage. One of the most striking cousequences of the application is the quiescence of the wound. The action which one would imagine must of necessity follow the application of an escharotic so powerful as the chloride of zinc, is never to he seen. The parts, up to the very edges of the wound, retain their natural colour during the early periods after an operation. I can state this confidently after the use of the lotion in varietics of operations, the removal of tumours, amputations, even with extensive and thin flaps, as Syme's and Mackenzie's amputation, operations about the rectum, involving the mucous membrane, and in the perineum, and in many others, as well as after accidental wounds. In many cases the wounds have healed in twenty-four hours, without the least fulness or swelling, and leaving a line of cicatrix which after a short time could hardly be seen or felt."

"That great pain sometimes attends the immediate application to a sensitive wonnd need not be mentioned. But this is not lasting. In most cases it subsides in from one to two hours; in some cases it does not occur at all. Where the application is made after an operation donc under chloroform, the patient generally remains altogether free from pain. This is particularly the case when morphia has been subcutaneously injected, as Mr. Moore first suggested, immediately the opcration is concluded, and before the effects of the chloroform have passed off. After this procecding the patient often remains calmly asleep for some hours, and wakes cntirely free from pain. There scems to be also less tendency to sickness. When, however, the immediate pain of the application has once subsided, the comfort which the patient enjoys is very striking. I have secn cases in which the patients could not tell from their scnsations after a couple of hours that any operation had heen done. One can explain, perhaps, from observing the action of the chloride, why action and consequent pain should be lessencd or altogether prevented. It is quite clear that tlie chloride of zinc does not act as an irritant beyond the point of contact. If its nse is carried so far as to produce an eschar. the eschar will act as an irritating body, and there will be inflammation and swelling around it; but if applied short of this, and it requires a continued application of the solid chloride to make an eschar in the natural structures, it produces a peculiar pulpy state of tissue, widely different no doubt from the natural tissue; but certainly not eschar, not a charred mass which must be removed by the ordinary process of separation below and around it. Were the surface of a large wound converted into an eschar, it could not heal in twenty-fonr hours. And yct the tissue appears disintegrated; it is rapidly discharged as a creamy exudation, leaving the parts hclow perfectly natural in appearance. This can easily be seen when the lotion is applied to an open wound. In this creamy surface must be involved all the sensitive and vasculo-motor nerves, and their function must be arrested. With many escharotics, as the actual cautery, the acids, \&c., the irritating effect is propagated along the nerves beyond the point of eontact. Although the nerves exposed on the surface may be destroyed, the effect is carried beyond this point, increased nerve action and inflammation is the result. It is not so with the chloride of zinc. From whatever cause it may be, the action terminates at the point of contact. The sensitive surface is destroyed, but no irritation is set up heyond the part directly acted upon. Hence there is no pain, no vascular action, no inflammation. Whether this is or is not the true explanation, the fact certainly is as I have stated it.

"Of course I do not mean to assert that all this immunity will be found in evcry case; but I can safely say that I have never secu it otherwise, and that, as a 
rule, I have never seen the general run of cases go throngh so favonrable a course as since I used this application.

"The mode of application has been described in connection with the first casc in which I tried the solution. The first cffect is always to stimulate the small vessels and cause a general oozing of blood from surfaces which had been previously dry. The blood becomes pink and creamy by contact with the chloride. On further application of the solution the whole surface is softened and assumes the same pink colour. The blood will continue to ooze out as long as the solution is applied, and for a short time after. Every part should be well saturated with the chloride-the edges of the skin, the adipose tissue, the spaces between the muscles, the medullary cavity, or cancellated structure of bone. At first I was afraid to touch bone with it, but I find now that no harm comes of doing so. The surgeon need not hesitate to apply it even to thin and clelicate structures. Those cases have done best in which it has bcen most thoronghly userl. For wounded surfaces I generally use a solution of from thirty to forty grains to the ounce of water."

24. Subcutaneous Olceration.-By $\overline{\mathbf{J}}_{\mathrm{AS}}$. PAGFT (extracted from a clinical lecture). Among the frequent effects of inflammation are, the separations of adjacent lajers of different tissues. Some of these deserve special notice for their practical importance. The simplest examples of this dissevering process are those in which one finds the capsule of the kiduey more than usually scparable, or the periostenm too easily stripping from the bone. In these cases thcre may be no more morbid change than that of softening of the walls of resscls, and the small quantity of connective tissue, which naturally hold together the two parts. A greater change is effected when articular cartilage can be stripped from bone; for here the separation is not possible till after the ulceration or extreme softening of one or both of the adjacent layers. In some of these cases it is observable that the disseverance of the bone and cartilage is without apparent formation of pus, or other morbid fluid. The cartilage, usually ulcerated on jts under surfuce, can be raised from contact with the nlcerated bone, or the thin layer of granulations covering the bonc, and no pus visible to the naked eye lies between them. This manner of dissevcrance by ulceration of bonc and cartilage is generally known; it is a common result of acute inflammation of the joints. A similar process sometimes scparates the subentaneous fat from the subjacent fascia. It may fairly be called subcutaneous ulceration, to distinguish it from that with which it is mostly confoundednamely, the diffuse suppuration of the subcutaneous fat. There are truly several points of resemblance between the two processcs, as there are betwecn all instances of suppuration and ulceration; but a manifest difference is in thisthat in the one the supptrative, in the otlier the ulcerative, process is greatly preponderant. In the diffuse suppuration, the pus forms an evideut collection of fluid more or less widely separating the lajers and upraising the skin; but in the ulceration, the separated layers remain in contact, or with only a little fluid between them. With these differences, others equally marked coincide in the general condition of the patients, and in the course and neccssary treatment of the local disease. In the girl now under treatment, the disease appeared, when she was admitted into the hospital on August 15 of last year, as an illdefined patch of mottled, dusky redness, larger than one's hand, across the front of the lower part of the thigh. This patch of discased integument was scarcely raised above the surrounding level. To the touch, it felt firm and brawny, but unequally so in different parts. It was hot. but not very painful, and at only one or two points tender npon pressurc. Higher up in the onter part of the thigh were two scars, said to have becn formed after similar disease there. The patient's general condition was that of mere debility, and that not extrcme. She had no fever, no hectic, no rigors, and, except after a slight attack of pneumonia, she scarcely lost weight or strength. A variety of different modes of treatment were all equally uscless for the remcdy of this state. Complete rest, blisters, ointment of iodide of mcrcury, and the internal use of iron, iodide of potassium, cod-liver oil, had no sensible effect. At length, one of the places at which tenderness lad been long observed was found solt as if 